\title{
Hand replantation: First experience in a sub-Saharan African country (Togo)
}

\author{
Komla Sena Amouzou, Komla Amakoutou, Batarabadja Bakriga, Anani Abalo, Assang Dossim \\ Department of Orthopedics, Traumatology, Plastic and Reconstructive Surgery, Sylvanus Olympio Teaching Hospital, \\ BP 57 Lomé, Togo
}

Address for correspondence: Dr. Komla Sena Amouzou, Department of Orthopedics and Traumatology, Plastic and Reconstructive Surgery, Sylvanus Olympio Teaching Hospital, 02BP 20752, Lomé, Togo. E-mail: alain.amouzou@gmail.com

\section{ABSTRACT}

Fifty years after Chen has performed the first forearm replantation, we report our first case of hand replantation in a sub-Saharan African country. The etiology of the amputation was machete due to interpersonal violence. The amputation was trans-carpal, guillotine-type, subtotal non-viable maintained with a small skin bridge. The replantation procedure was successful. At one year follow-up, the functional result according to Chen's criteria was excellent. Through this first experience, we can state that hand replantation can be performed successfully both in survival and function in a non-specialized hospital of a sub-Saharan African country.

\section{KEY WORDS}

Africa; hand; replantation; Togo

\section{INTRODUCTION}

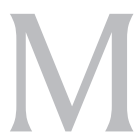

acroreplantations refer to amputations proximal to wrist or ankle joints. When there is evidence of a residual circulation the term revascularisation is used. ${ }^{[1]}$ Since the first successful replantation of an arm in 1962 by Malt and McKhann in Boston and forearm in 1963 by Chen et al. in Shanghai, ${ }^{, 2,3]}$ the procedure has become common in developed countries. Replantation and revascularisation surgery requires the existence of a specialised centre, well-trained teams and microsurgeons, something that is not always available in sub-Saharan countries where refashioning and closure of the amputation stump are the common

\begin{tabular}{|l|l|}
\hline \multicolumn{2}{|c|}{ Access this article online } \\
\hline Quick Response Code: & Website: \\
\hline & www.ijps.org \\
\hline & \\
\hline
\end{tabular}

surgical procedures..$^{[4,5]}$ To the best of our knowledge, except in the Republic of South Africa, no case of hand replantation has been reported in a sub-Saharan country till now.

We report a case of hand replantation with 1-year follow-up.

\section{CASE REPORT}

A 17-year-old right-hand dominant male student was transferred to our traumatology Emergency Department (ED) on the $13^{\text {th }}$ December 2012, $5 \mathrm{~h}$ after his left hand had

This is an open access article distributed under the terms of the Creative Commons Attribution-NonCommercial-ShareAlike 3.0 License, which allows others to remix, tweak, and build upon the work non-commercially, as long as the author is credited and the new creations are licensed under the identical terms.

For reprints contact: reprints@medknow.com

How to cite this article: Amouzou KS, Amakoutou K, Bakriga B, Abalo A, Dossim A. Hand replantation: First experience in a subSaharan African country (Togo). Indian J Plast Surg 2016;49:109-11. 
been amputated in a knife fight. He was non-smoker with a poorly controlled seizure disorder. His left hand had been sharply amputated at the level of zone $V$ with only a skin bridge at the lateral border of the wrist. X-ray showed that the amputation was through the distal third of scaphoid, capitate, hamate and base of the fifth metacarpal [Figure 1]. He had no other injuries. We immediately wrapped the hand in a fabric-containing ice to minimize warm ischaemia after we put a vascular shunt on the radial artery (use of a venous catheter 14-gauge) in the ED.

As the patient desired to keep his hand and his mother signed the consent form, the decision to attempt replantation was taken at the $7^{\text {th }} \mathrm{h}$. The team consisted of plastic surgeon, anaesthesiologist and two theatre nurses. The procedure was done with nerve-block anaesthesia followed by general anaesthesia.

The patient was kept in a warm room with a postoperative orthosis and the hand elevated. The hand's circulation was monitored postoperatively by clinically observing for ischaemia signs. There were no vascular complications and no need for blood transfusion. A neurologist ordered anti-seizure protocol. We started low molecular weight heparin intraoperatively which was continued for 1 week, and aspirin (100 mg) was given for 1 month. Broad-spectrum antibiotique (cephalosporin and aminoside) were given intravenously for 5 days. On the $30^{\text {th }}$ postoperative day, a superficial infection appeared at one K-wire site and was treated with broad-spectrum antibiotics and K-wire removal.

On the third post-operative day passive motion of the shoulder, elbow and digits was commenced. On the $10^{\text {th }}$ day, the active motion of the wrist and digits was initiated within the confines of the orthosis by physiotherapy. At 3 weeks, the orthosis was removed for exercises and put for the rest of the day. At 6 weeks, the splint was totally removed. Special exercises to assist with activities of daily living were also done. Grip strength, forearm strengthening with rollers was

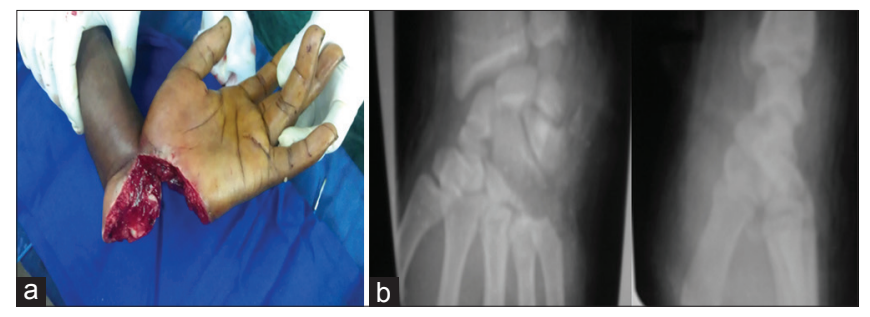

Figure 1: (a) Subtotal non-viable left-hand amputation, (b) pre-operative X-ray showing fracture of scaphoid, capitate, hamate and parcelar articular fracture of the base of the fifth metacarpal used. Manual resistive strengthening for intrinsic and extrinsic muscles was done. All this protocol was used continuously for 4 months. However, it was difficult to maintain this regularly for the next 6 months because of the patient's uncontrolled seizure disorder and social condition. General anaesthesia was needed twice for the passive joint motion because of pain. No secondary surgical procedures were performed.

Functional evaluation was done at one year post replantation [Figure 2]. The patient recovered static two-point discrimination of $20 \mathrm{~mm}$ in all three peripheral nerves. His pinch strength was $50 \%$, and grip strength was $40 \%$ of the opposite side. He had $45^{\circ}$ of the active wrist with flexion and $35^{\circ}$ of active wrist extension. Active range of motion in all fingers was $200^{\circ}$ and thumb active range of motion was $130^{\circ}$. Intrinsic muscle function was good. The patient used the replanted hand for most daily tasks and some precise activities without pain or instability. The patient was highly satisfied with the result. He returned to the school.

\section{DISCUSSION}

In sub-Saharan countries, treatment of the majority of upper limb amputations is stump closure. ${ }^{[4,5]}$ Reasons include ignorance, poverty, late presentation to the hospital, lack of proper care of amputated parts, lack of proper supplies at the hospital such as microsurgical sutures, instruments and magnification. Other relevant factors in Africa are the scarcity of hand surgeons, poor experience of surgeons and lack of a trained replantation team. The sequence of repair is directly influenced by the amount of muscle mass in the amputated part and ischaemia time. ${ }^{[6]}$ In our case, warm ischaemia time was $5 \mathrm{~h}$ supported by a vascular shunt by the $6^{\text {th }} \mathrm{h}$.

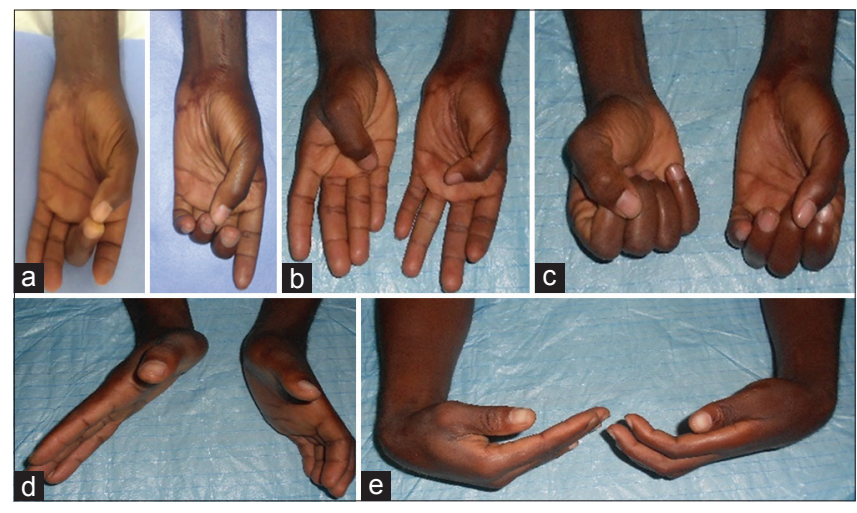

Figure 2: (a) Pollicidigital pinch, (b) thumb opposition, (c) grip strength, (d) wrist extension and (e) wrist flexion 
Psychological or neurologic illness has been cited as a contraindication to replantation. ${ }^{[7]}$ Although our patient was epileptic, he did not develop any complication as a consequence of this.

Weachieved a functional hand replantationina sub-Saharan country just similar to other countries ${ }^{[8]}$ probably because of the age the patient, the use of arterial shunt to reduce the ischaemia time and meticulous reparation of all tissues and hard work of physiotherapist. Through this first experience, we can state that hand replantation can be performed successfully both in survival and function in a non-specialised hospital of a sub-Saharan African country. This may be the beginning of a replantation team and populations need to be educated about conditions in order for replantation to be attempted.

\section{Financial support and sponsorship}

Nil.

\section{Conflicts of interest}

There are no conflicts of interest.

\section{REFERENCES}

1. Biemer E. Definitions and classifications in replantation surgery. Br J Plast Surg 1980;33:164-8.

2. Malt RA, Mckhann C. Replantation of severed arms. JAMA 1964;189:716-22

3. Chen CW, Chien YC, Pao YS. Salvage of the forearm following complete traumatic amputation: Report of a case. Chin Med J (Engl) 1963;82:633-8.

4. Onuba $\mathrm{O}$, Udoidiok $\mathrm{E}$. The scope of amputation in developing countries. Postgraduate Doctor-Africa, 1989;11;118 - 21.

5. Omoke NI, Chukwu CO, Madubueze CC, Egwu AN. Traumatic extremity amputation in a Nigerian setting: Patterns and challenges of care. Int Orthop 2012;36:613-8.

6. Sabapathy $S R$, Venkatramani $H$, Bharathi RR, Bhardwaj P. Replantation surgery. J Hand Surg Am 2011;36:1104-10.

7. Goldner RD, Urbaniak JR. Indications for replantation in the adult upper extremity. Occup Med 1989;4:525-38.

8. Patel AA, Blount AL, Owens PW, Askari M. Functional outcomes of replantation following radiocarpal amputation. J Hand Surg Am 2015;40:266-70. 